\title{
6-OHDA ile Oluşturulan Parkinson Hastalığı Modelinde Astrogliozis ve Glutamat Taşıyıcı Protein GLT1 Ekspresyonu
}

\author{
Zehra MíNBAY ${ }^{1}$, Bülent GÖREN ${ }^{2}$, Özhan EYİGÖR ${ }^{1}$ \\ 1 Bursa Uludağ Üniversitesi Tıp Fakültesi, Histoloji ve Embriyoloji Anabilim Dalı, Bursa. \\ 2 Bursa Uludağ Üniversitesi Tıp Fakültesi, Fizyoloji Anabilim Dalı, Bursa.
}

\section{ÖZET}

Substansiya nigra pars kompakta yerleşik dopamin nöronlarının kaybı ile karakterize Parkinson hastalığında nöron ölümüne neden olan mekanizmalar tam olarak anlaşılamamış olsa da, bazı kanıtlar hastalığın patogenezinde glutamaterjik sistemin rol oynadığını göstermektedir. Merkezi sinir sisteminin (MSS) ana eksitatör nörotransmitteri olan glutamatın sinaptik aralıktaki konsantrasyonunun yükselmesi eksitotoksisiteye neden olmaktadır. Nöronları glutamat kaynaklı toksisiteden koruyan ana mekanizma, eksitatör amino asit taşıyıcıları olarak bilinen plazma membran proteinlerinin aracılık ettiği alım sistemi yoluyla sinaptik glutamatın ortamdan uzaklaştırılmasıdır. Bu taşıyıcıların disfonksiyonunun bazı nörodejeneratif hastalıklarla ilişkili olduğu gösterilmiştir. Bu çalışmada, 6-hidroksidopamin (6-OHDA) ile oluşturulan deneysel Parkinson modelinde astrositlerde ve GLT1 ekspresyonundaki olası değişikliklerin ikili immünohistokimyasal yöntem ile gösterilmesi amaçlandı. Denekler rasgele iki gruba ayrıldı ve streotaksik olarak intranigral serum fizyolojik ya da 6-OHDA enjeksiyonu yapıldı. 15 gün sonra yapılan rotasyonel testlerin ardından denekler sakrifiye edildi ve çıkarılan beyinlerden alınan yüzen kesitler ikili immünofloresans ve ikili indirekt immünoperoksidaz yöntemleri kullanılarak sirasıyla glial asitik fibriler protein (GFAP)-GLT1 ve tirozin hidroksilaz (TH)GFAP antikorları ile işaretlendi. İntranigral 6-OHDA enjeksiyonu dopaminerjik nöron kaybına neden olurken, glial hücre gövdelerinde genişleme astroglial uzantılarda sayı ve çap artışı gözlendi (glial reaksiyon). Glial reaksiyona klasik intermediyet filament belirteci olan GFAP up-regülasyonu eşlik ediyordu. 6-OHDA uygulanan grupta astrositik aktivasyona karşın GLT1 ekspresyon yoğunluğunun değişmemesi, GLT1 down-regülasyonu olarak değerlendirildi. Sonuç olarak; SNpc'da 6-OHDA ile oluşturulan dopaminerjik nöron hasarı sonrası immünohistokimyasal yöntemlerle belirlediğimiz astrogliozis ve astrositik aktivasyona karşın GLT1 proteininin artış göstermemesi, astrositlerin ve/veya glutamat taşıyıcısı GLT1'in, SNpc'da dopaminerjik nöron ölümü ile karakterize Parkinson hastalığının etyopatolojinde rol oynayabileceğini ve ayrıca astrositlerin sağkalımı ve fonksiyonlarının korunmasının, nöron kaybı ile karakterize MSS hastalıklarının sağaltımı için yeni terapötik ajan arayışına yönelik çalışmalar için hedef yaklaşımlar olabileceğini düşündürmüştür.

Anahtar Kelimeler: Substansiya nigra. Dopaminerjik nöronlar. Astrogliozis. Eksisitotoksisite. GLT1.

Astrogliosis and Glutamate Transporter Protein GLT1 Expression in 6-OHDA induced Parkinson's Disease Model

\section{ABSTRACT}

Although the mechanisms that cause neuronal death are not fully understood in Parkinson's disease, which is characterized by the loss of dopamine neurons located in the substantia nigra pars compacta, some evidence suggests that the glutamatergic system plays a role in the pathogenesis of the disease. The increase in the concentration of glutamate, the main excitatory neurotransmitter of the central nervous system (CNS), in the synaptic gap causes excitotoxicity. The main mechanism that protects neurons from glutamate-induced toxicity is the removal of synaptic glutamate through the uptake system mediated by plasma membrane proteins known as excitatory amino acid transporters. Dysfunction of these transporters has been shown to be associated with some neurodegenerative diseases. In this study, it was aimed to demonstrate the possible changes in astrocytes and GLT1 expression in the 6-hydroxydopamine (6-OHDA) induced Parkinson's disease model by dual immunohistochemical method. The rats were randomly divided into two groups and injected stereotactically with intranigral saline or 6-OHDA. Rotational tests were performed 15 days after the injections and then the rats were sacrificed. Free floating sections were labeled with glial acidic fibrillar protein (GFAP)-GLT1 and tyrosine hydroxylase (TH)-GFAP antibodies using dual immunofluorescence and dual indirect immunoperoxidase methods, respectively. While intranigral 6-OHDA injection caused loss of dopaminergic neurons, enlargement of the glial cell bodies and an increase in the number and diameter of the astroglial extensions (glial reaction) were assessed. Furthermore, the glial reactivity was accompanied by upregulation of the synthesis of glial fibrillary acidic protein which is intermediate filament protein of astrocytic cytoskeleton. The fact that no changes in the density of GLT1 expression was found in SN in despite of glial activation in the rats injected with 6-OHDA was evaluated as down-regulation of GLT1. After dopaminergic neuron damage induced by 6OHDA in SNpc, the fact that astrogliosis and despite of astrocytic activation GLT1 protein did not increase suggest that astrocytes and/or glutamate transporter GLT1 may play a role in the etiopathology of Parkinson's disease, which is characterized by dopaminergic neuron death in SNpc. This also suggests that the survival and function of astrocytes may be targeted approaches for studies to seek new therapeutic agents for the treatment of CNS diseases characterized by neuronal loss.

Key Words: Substantia nigra. GLT1. Astrogliosis. Dopaminergic neurons. Excitotoxicity.

Geliş Tarihi: 11.Kasım.2020

Kabul Tarihi: 07.Aralık.2020

Dr. Zehra MiNBAY

Bursa Uludağ Üniversitesi Tıp Fakültesi, Histoloji ve Embriyoloji Anabilim Dall,

Bursa.

Tel: 02242954064

E-posta: zminbay@uludag.edu.tr
Yazarların ORCID ID Bilgisi:

Zehra MiNBAY: 0000-0001-5757-8450

Bülent GÖREN: 0000-0001-8061-8756

Özhan EYIGÖR: 0000-0003-3463-7483 
Dopamin nöronları, merkezi sinir sistemindeki (MSS) tüm nöronların ancak \%1'ini oluşturmalarına karşın, farklı anatomik pozisyon ve uzantıları ile organizmada motor kontrol, kardiovasküler, respiratuvar, gastrointestinal ve davranış aktivitelerinin düzenlenmesinde rol oynarlar ${ }^{1-3}$. Bu nöronların \%90'inı oluşturan en büyük bölümü, mezensefalonun ventral bölgesindeki retrorubral alan, substansiya nigra $(\mathrm{SN})$ ve ventral tegmental alanda (VTA) yerleşiktir ${ }^{2,4}$. SN, nörokimyasal ve fonksiyonel olarak birbirleri ile ilişkili iki ana nöron grubundan oluşur: Hücre gövdeleri substansiya nigra pars kompaktada $(\mathrm{SNpc})$ yerleşik nigral dopaminerjik nöronlar ve bazal ganglion devresinin çıkışı olarak kabul edilen substansiya pars retikülatada (SNpr) yerleşik olan GABAerjik nöronlar-8. Nigral dopaminerjik nöronların aktiviteleri beynin çeşitli bölgelerinden gelen inhibitör ve eksitatör girdiler ile düzenlenir ${ }^{9}$. SNpc'nın glutamaterjik girdileri (input), özellikle pedunkulopontin çekirdek ${ }^{9}$ ve subtalamik nukleusdan (STN) $)^{10-12}$ gelir.

Merkezi sinir sisteminin majör eksitatör amino asit nörotransmitter olarak kabul edilen glutamat ${ }^{13}$ presinaptik terminallerdeki veziküllerden sinaptik aralığa salındıktan sonra reseptörlerine bağlanarak organizmada pek çok ara metabolizmada anahtar rolü oynar. Ancak, glutamat aynı zamanda potent bir nörotoksindir $^{14}$. Sinaptik aralıktaki konsantrasyonunun yüksek kalması, glutamat reseptörlerinin aşırı uyarılmasının sonucu olarak, kalsiyum homeostazının bozulması, mitokondrial disfonksiyon, membran yıkımı, hücre iskeleti değişimleri, nitrik oksit sentezinin artması, sitoplazmadaki katabolik süreçlerde işlev gören kalsiyum bağımlı proteazların aktivasyonu, sitotoksik transkripsiyon faktörleri ve serbest radikallerin artışı gibi zarar verici mekanizmalar üzerinden nöron hasarı ve ölümüne neden olur ${ }^{14-20}$. Bu nedenle MSS'de glutamat seviyesinin regülasyonu, gerek bir sonraki aksiyon potansiyalinin yayılması gerekse glutamat reseptörlerinin aşırı uyarılmasının engellenmesi için gerek$\operatorname{lidir}^{15,16,18}$. Glutamatın sinaptik aralıktan uzaklaştırılmasında majör sorumlu, $\mathrm{Na}^{+}$-bağımlı, yüksek afiniteli alım (taşıyıcı-aracılı alım) mekanizmasıdır. Bu alım, eksitatör amino asit taşıyıcıları (EAAT) olarak bilinen ve nöronlar ile astrositlerde bulunan membran proteinleri aracıllı̆̆ıla gerçekleşir ${ }^{15,16,21,22}$ Günümüzde astrositler ve/veya nöronlar tarafindan eksprese edilen beș plazma membran glutamat taşıyıcısı alt tipi tanımlanmıştır. Siçan beyninden klonlanan astrositik $\mathrm{Na}^{+}$bağımlı glutamat taşıyıcıları, GLAST (EAAT1) ve GLT1 (EAAT2) olarak adlandır1lırlar ${ }^{22,23}$. GLAST, MSS gelişimindeki ana taşıyıcı protein olup erișkinde özellikle beyinciğin Bergmann gliası tarafindan eksprese edilir ${ }^{16}$. GLT1 (EAAT2) postnatal dönemde eksprese edilen ana glutamat taşıtıcısıdır ve erişkinde tüm glutamat transportunun \%90'indan sorumludur ${ }^{14}$. Glutamat taşıyıcı ailesinin diğer üyeleri olan EAAC1, EAAT4 ve EAAT5 nöronal glutamat taşıyıcıları olup ve postsinaptik membranlarda yüksek yoğunlukta bulunur ${ }^{24-27}$.
Merkezi sinir sisteminin değiş̧ik seviyelerinde, glutamaterjik ve dopaminerjik sistemler arasında ilişki olduğu bilinmektedir. Morfolojik çalışmalar, glutamat içeren akson terminallerinin dopamin içeren bölgelerde bulunduğunu ve dopamin nöronları ile sinaps yap-

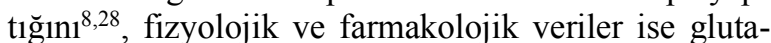
mat reseptörlerini uyaran glutamat ve antagonistlerinin dopamin nöronlarının aktivitesini etkilediğini ve dopamin salınımını düzenlediğini ${ }^{1}$, elektrofizyolojik ve farmakolojik çalışmalar da, $\alpha$-amino-3-hidroksi-5metil-4- izoksazolpropionik asit (AMPA) ve N-metilD-aspartat (NMDA) reseptörlerinin dopaminerjik nöron soma ve dendritlerinde yerleşimlerini göstermiştir ${ }^{29}$. SNpc'da lokalize dopaminerjik nöronların irreversibl, selektif ve ilerleyici dejenerasyonu, nörodejenetatif bir patoloji olan Parkinson hastalığında gözlenen karakteristik yapısal değişiklik olmakla birlikte $^{30,31}$ şizofreni, manik-depressif hastalık ve tardif diskinezi gibi affektif hastalıklarla da ilişkili bulunmuştur $^{20,32,33}$. Parkinson hastalığı, amyotrofik lateral skleroz (ALS), Alzheimer hastalığı gibi nörodejenetatif hastalıklarda nöron ölümüne neden olan mekanizma/lar tam olarak bilinmemekle birlikte glutamat metabolizması ve/veya transportundaki değişikliklerin bu hastalıkların etyolojisi ile ilişkili olduğu, ayrıca, glutamat taşıyıcı proteinlerin ekspresyonunun inhibe edilmesi ile eksisitotoksisite ve nörodejenerasyon geliştiği gösterilmiştiri ${ }^{31,34-40}$.

Normal beyinde nöronal ekstrasellüler çevrenin homeostatik kontrolünün primer sorumlusu olan astrositler, beyin hasarlarında gözlenen nörodejenerasyon ve nöroproteksiyonda da kritik rol oynarlar ${ }^{41}$. Beyindeki pek çok hastalığın en belirgin nöropatolojik özelliği astrogliozistir. Beyin hasarlarında hem morfolojik özellikleri hem de sentetik aktiviteleri değişerek reaktif hale gelen astrositler, hasarlı hücrelerden salınan $\mathrm{K}^{+}$ve artan ekstrasellüler glutamat konsantrasyonunu bazal değerlerine indirecek moleküllerin ekspresyonunu arttırırlar ${ }^{42}$, mikroglial aktivasyonu düzenleyerek aşırı enflamasyonu baskılarlar ${ }^{14}$ ve reaktif oksijen radikallerine hızla yanıt vererek nöronları ve sinir sisteminde yer alan diğer hücreleri korurlar ${ }^{41}$.

$\mathrm{Bu}$ bilgilerin ışı̆̆ altında çalışmamızda, 6-hidroksi dopamin (6-OHDA) ile olușturulan deneysel Parkinson modeli kullanılarak substansiya nigradaki dopaminerjik nöron kaybinda astrositlerde ve GLT1 ekspresyonundaki olası değişikliklerin immünohistokimyasal yöntemle gösterilmesi amaçlanmıştır.

\section{Gereç ve Yöntem}

Çalışma Bursa Uludağ Üniversitesi Hayvan Bakım ve Kullanım Komitesi tarafindan 29.12.2005 tarih ve 29.12.2005/1 no'lu kararı ile onaylanmıştır. Çalışmada Bursa Uludağ Üniversitesi Deney Hayvanları Yetiştirme ve Uygulama Merkezi'nden sağlanan, 15 adet 
Wistar albino erkek sıçan (300-350 gr) kullanıldı. Denekler, sıcaklığ $120-24^{0} \mathrm{C}$ 'de sabit tutulan ortamda ve 12 saat aydınlık (07:00-19:00) - 12 saat karanlık (19:00-07:00) döngüsünde ad libitum olarak su ve yemle beslendi.

\section{Lezyon Oluşturulması}

Çalışmada, SNpc'da dopaminerjik nöronların dejenerasyonunu indükleyebilmek için nörotoksin olarak 6OHDA kullanıldı ${ }^{43}$. Denekler rasgele iki gruba ayrıldı ve bir gruba tek taraflı intranigral \%0,9 $\mathrm{NaCl}$ (SF, 4 $\mu l)$ verilirken ( $\mathrm{SF}$ grubu, $\mathrm{n}=7$ ), diğer gruba serum fizyolojikte hazırlanmış 6-OHDA $(8 \mu \mathrm{g} / 4 \mu \mathrm{l})$ enjekte edildi (6-OHDA grubu, $\mathrm{n}=8$ ). Bu enjeksiyonlar için hazırlanan denekler sodyum pentotal anestezisi altında (40 mg/kg, ip) stereotaksik alete yerleştirildi. Cerrahi işlemler için gerekli olan asepsi-antisepsi koşulları sağlandıktan sonra, orta hat cilt insizyonunu takiben cilt altı fasyası açılarak, sagital ve koronal sutürler görüldü. Bregmaya göre, anteroposterior $-5 \mathrm{~mm}$, sol lateral $2 \mathrm{~mm}$ işaretlenerek el perforatörü ile $1 \mathrm{~mm}$ çaplı delik açıldı. Stereotaksik alete adapte edilen Hamilton enjektörü ile dura mater düzeyinden 7,4 mm derinlikte sol taraf SN bölgesine enjeksiyon $0,5 \mu \mathrm{l} / \mathrm{dak}$ hızında uygulandi. Enjeksiyon tamamlandiktan sonra enjektör $2 \mathrm{dk}$ süreyle yerinde tutuldu ve $2 \mathrm{~mm} / \mathrm{dk}$ hızla geri çekildi. Kraniumdaki delik kemik mumu ile kapatılarak insizyon yerine sutür konuldu.

\section{Enjeksiyon Sonrası Uygulanan Dönüş Testleri}

6-OHDA enjeksiyonun sonra lezyon oluşup oluşmadığını ve lezyonun neden olduğu motor bozukluğun derecesini izlemek amacıyla deneklere dönüş testleri yap $1{ }^{1} 1^{44}$. Bu amaçla, enjeksiyonlardan 15 gün sonra deneklere önce intraperitoneal amfetamin sülfat $(5 \mathrm{mg} / \mathrm{kg})$ verilerek $360^{\circ}$ 'lik ipsilateral tam dönüşleri ve bu uygulamadan 24 saat sonra apomorfin hidroklorid $\left(0,1 \mathrm{mg} / \mathrm{kg}\right.$, subkutan) verilerek $360^{\circ}$ 'lik kontrolateral tam dönüşleri kaydedildi. Dönüş testleri ile Parkinson modeli oluştuğu belirlenen denekler çalışmaya dahil edildi. Kayıt edilen dönüş değerlerin standart istatistiksel analizleri için Student-t testi kullanıldı. $\mathrm{p}<0,05$ anlamlı kabul edildi.

\section{Dokuların Hazırlanmast}

Dönüş testleri tamamlanmasının ardından derin anestezi altındaki denekler kalp apeksinden aortaya yerleştirilen bir kateter aracılığıyla 0,13 M Sorenson'un fosfat tamponu ile hazırlanan fiksatif $\% 4$ paraformaldehit, (400 ml/denek) ile transkardiyak perfüzyon fiksasyonu yöntemi ile sakrifiye edildi. Perfüzyon sonrası deneklerin kraniyumları açılarak beyinleri çıkarıldı. Çıkarılan beyinler aynı fiksatifte hazırlanan $\% 10$ sükroz solüsyonunda tüm gece, $0,13 \mathrm{M}$ fosfat tamponda (pH 7,4) hazırlanan $\% 20$ ve $\% 30$ sükroz solüsyonlarında ise ikişer gün bekletildi. Beyinler dondurulduktan sonra, kriyostat ile 5 seri olacak şekilde alınan $30 \mu$ m'lik kesitler kullanılıncaya kadar kriyoprotektan içerisinde $-20^{\circ} \mathrm{C}$ 'de sakland.

\section{Immunohistokimya}

6-OHDA ile Olușturulan Lezyonun ve Astrositik Değișikliklerin Belirlenmesi: İlk olarak SNpc'da oluşturulan lezyonu ve lezyon alanındaki astrositlerin morfolojisi, dağılımı ve yoğunluğunu belirlemek amacıyla aşağıda belirtilen yöntemle ikili immünoperoksidaz boyaması yapıldı. Her iki grupta da intranigral enjeksiyon tarafındaki dopaminerjik nöron hasarını göstermek ve sağlam substansiya nigra tarafi ile farkını belirlemek amaciyla, dopamin sentezinin birinci basamağında rol alan tirozin hidroksilaz $(\mathrm{TH})$ enzimini tanıyan antikor ve astrositlerde gözlenen değişiklikleri gözlemlemek amacıyla da bu hücreler için belirteç olarak kullanılan glial asitik fibriler protein (GFAP) antikoru kullanıld. Tris-HCl tamponu ile yıkanarak kriyoprotektandan arındırılan kesitler, normal bloklayıcı serum (\%10 at serumu) ile 2 saat inkübasyonu takiben fare anti-GFAP (1:5,000; Sigma, Clone G-A-5, G3893, St Louis, MO, USA) solüsyonunda 48 saat bekletildi. Primer antikordan sonra biyotin konjuge eşek anti-fare IgG (1:200; Jackson ImmunoResearch Laboratories, Inc. West Grove, PA) ile 2 saat sekonder antikor uygulaması yapıldı. Ardından kesitler avidin biyotin kompleksi (ABC Elite Kit, Vector Labs, Burlingame, CA) solüsyonu ile 1 saat inkübe edildi. Oluşan kompleks nikel-diaminobenzidin (Ni-DAB) substrat kromojen solüsyonu ile işleme tabi tutuldu. Yıkanan kesitler tavşan anti-TH (1:3,000; AB152, Chemicon International Inc., Temecula, CA USA) antikoru tüm gece inkübasyon öncesi tekrar normal bloklayıc1 serumda 2 saat süreyle bekletildi. Sirasıyla biyotinli eşek anti-tavşan IgG'de (1:200; Jackson ImmunoResearch Laboratories, Inc. West Grove, PA USA) 2 saat ve avidin biyotin kompleksi solüsyonu ile 1 saat inkübasyon sonrası reaksiyon nikel içermeyen DAB ile görünür hale getirildi. Y1kanarak lamlara alınan kesitler kurutuldu ve dibütilfitalat polistiren ksilen (DPX) ile kapatıldı.

SNpc'da GLT1 Ekspresyonunun Belirlenmesi - İkili İmmünofloresans Yöntemi: Bu amaçla $30 \mu \mathrm{m}$ kalınlığındaki yüzen kesitlere ikili immünofloresans işaretleme yöntemi uygulandı. Tris-HCl tamponu yıkanan kesitler, bloklayıcı serum içerisinde 2 saat bekletildi. Takiben astrosit ve GLT1'i eş zamanlı işaretlemek amaciyla, fare anti-GFAP (1:1,000; Sigma, Clone GA-5, G3893, St Louis, MO, USA) ve kobay antiGLT1 (1:2,000; AB1783 Chemicon International Inc. Temecula, CA USA) antikorlarını içeren primer antikor karışımı ile oda sıcaklığında 48 saat inkübe edilen kesitler yıkandıktan sonra FITC işaretli eşek antitavşan IgG (1:300; Jackson ImmunoResearch Laboratories, Inc. West Grove, PA USA) ve Cy3 işaretli eşek anti-kobay (1:400; Jackson ImmunoResearch Labora- 
tories, Inc. West Grove, PA USA) sekonder antikorlarını içeren solüsyonda 2 saat bekletildi. Kesitler lamlara alınarak kurutuldu ve incelemeden hemen önce kapatma materyali (Prolong Gold Antifade Kit, Molecular Probes, Oregon USA) ile kapatıldı.

\section{İstatistiksel Analiz}

Histolojik olarak değerlendirilecek kesitlerin aralığ Paxinos'un sıçan beyin atlasına ${ }^{45}$ göre belirlendi. Buna göre en rostralde bregma $-4,8 \mathrm{~mm}$, en kaudalde ise bregma $-6,36$ mm'ye uyan SN kesitleri kullanıldı. Bu aralıkta rostrokaudal düzlemde SN'nin 5 farklı seviyesinden alınan kesitlerde sayım işlemleri yapıldı. Kesitlerin tüm denekler için aynı koordinatta olmasına dikkat edildi. Sayımlar 20X objektif kullanılarak dijital kamera ile bilgisayar ekranına alınan görüntüler üzerinde gerçekleştirildi. Belirlenen kesitlerde intranigral enjeksiyon uygulanan SNpc'nın dorsal bölümünde GFAP immünoreaktif astrositler sayıldı. Deneklere ait sayısal verilerden ortalama ve standart hata (SEM) hesapland. İntranigral 6-OHDA uygulanan grupla SF uygulanan grup arasındaki karşılaştırmada Mann Whitney-U testi kullanıldı. $\mathrm{p}<0,05$ anlamlı kabul edildi.

GLT1 immünoreaktivitesinin GFAP-pozitif astrositlerdeki yoğunluğu yarı-kantitatif metot ile incelendi. GFAP ve GLT1 için uygulanan ikili immünofloresans boyamalarda değişkenleri en aza indirmek üzere tüm kesitler aynı solüsyonlarla (tampon, antikorlar ve diğer solüsyonlar) aynı anda boyandı. Her iki gruptan deneklerin enjeksiyon uygulanan taraflarından SN'lerin görüntüleri (4080x3072 piksel boyutunda), mikroskoba (Olympus BX-FLA floresan ataşman takılı Olympus BX50) adapte edilmiş dijital kamera (Olympus DP71, 1,5 million pixel) kullanılarak 20X objektifle aynı koşullar altında (eş pozlama süresi) elde edildi. Dijital görüntüler elde edilirken optik kesit kullanılmadı başka bir deyişle tek fokusta fotoğraflama işlemi yapıldı. Floresan yoğunluğunu belirlemek için yukarıda koordinatları verilen aralıkta denek başına beş kesitin dijital görüntüsü elde edildi. Her kesitte de dijital analiz programı (Imaje J) kullanılarak $255 \times 255$ piksel boyutunda alan seçici ile rasgele 5 alanda tüm nöropilar elemanlar kapsayacak şekilde ölçüm yapıld1 ${ }^{46,47}$. Floresan yoğunluğu programda belirlenen "ortalama gri değer" olarak ifade edildi. Her denek için 5 kesitten elde edilen değerlerden gruplar için ortalama ve SEM hesaplandı. Gruplar arası karşılaştırmada Mann Whitney-U testi kullanıldı.

\section{Bulgular}

\section{Dönüş Testleri}

İntranigral SF ve 6-OHDA enjeksiyonundan 15 gün sonra sistemik olarak uygulanan amfetamini takiben deneklerde ipsilateral tam dönüş değerleri sırasıyla yaklaşık 23 dönüş/saat ve 677 dönüş/saat olarak kay- dedildi. İstatistiksel değerlendirme sonucunda iki grup arasında fark anlamlı bulundu (Şekil 1). Amfetamin enjeksiyonundan 24 saat sonra uygulanan apomorfin sonrası kontralateral dönüş değeri SF grubunda ise 7 dönüş/saat, 6-OHDA grubunda yaklaşık 246 dönüş/saat olarak belirlendi. İki grup arasındaki fark istatistiksel olarak anlamlı bulundu (Şekil 1). Apomorfin enjeksiyonundan sonra dönüş değerlerinin düzelmemesi deneysel Parkinson modeli oluştuğunu gösterdi.

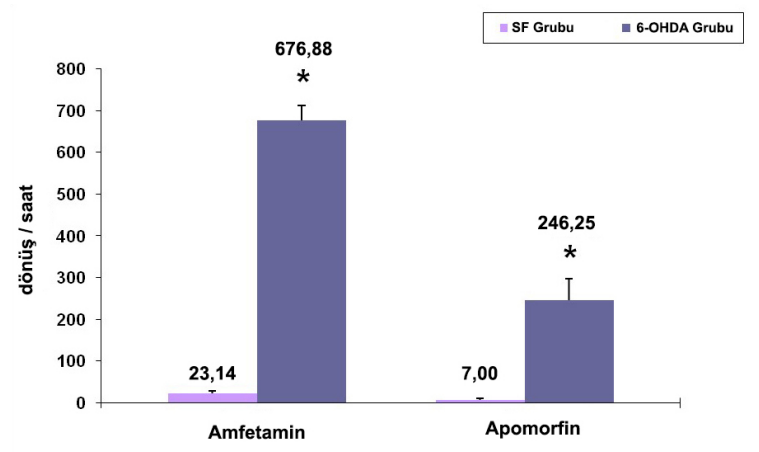

Sekil 1.

Deneklerin rotasyonel test sonuçlart ve istatistiksel karşılaştırmast. Değerler ortalama \pm SEM olarak verilmiştir. * $p<0,0001$ kontrol grubuna göre.

\section{6-OHDA ile Oluşturulan Lezyonun ve Astrositik Deği- şikliklerin Belirlenmesi}

İkili immünohistokimyasal boyamalar değerlendirildiğinde hem SF grubunda (Şekil 2A, B) hem de intrastriatal 6-OHDA uygulanan deneklerin sağlam taraflarındaki (Şekil 2D, E) SNpc'da TH immünoreaktivitesi (TH-IR) dopaminerjik nöronların somalarında kahverengi olarak izlendi. Ek olarak tüm SN'de çok sayıda nöronal uzantıda da TH-IR gözlendi ve dopaminerjik nöronların bu uzantıları SNpr'in neredeyse tamamında izlendi (Şekil 2A, D). Büyük büyütmede, nöronlardaki immünoreaktivitenin diffüz olduğu gözlendi (Şekil 2B, C, E). SF grubunda enjeksiyon yapılan SNpc'da tarafinda dopaminerjik nöron sayısında değişiklik izlenmezken (Şekil 2B, C) 6-OHDA enjeksiyonu sonrası SNpc'da dopaminerjik nöronların neredeyse tamamının yok olduğu belirlendi (Şekil 2D-F).

GFAP immünoreaktivitesinin değerlendirildiği kesitlerde, beklenildiği gibi her iki grupta sağlam tarafta SNpr'te çok sayıda GFAP immünoreaktif (GFAP-IR) hücreye rastlanırken SNpc'da sadece bir kaç hücre belirlendi (Şekil 2A, B, D, E, Şekil 3, Şekil 4A, D). GFAP-IR hücreler, SF grubunda iğne skarında belirginken, 6-OHDA verilen deneklerde iğne skariyla birlikte tüm SNpc'da izlendi. Sağlam tarafa oranla her iki grupta da astrosit sayısında artış belirgindi (Şekil $2 \mathrm{~B}-\mathrm{C}$ ve E-F, Şekil 4A, D). İntranigral SF ve 6-OHDA uygulanan gruplarda enjeksiyon tarafindaki ortalama astrosit say1s1 sirasiyla $188,2 \pm 30,5$ ve $423,3 \pm 16,7$ olarak bulundu. İstatistiksel değerlendirme sonucu iki grup arasındaki farkın anlamlı olduğu belirlendi $(p<0,0012)($ Şekil 3C). 


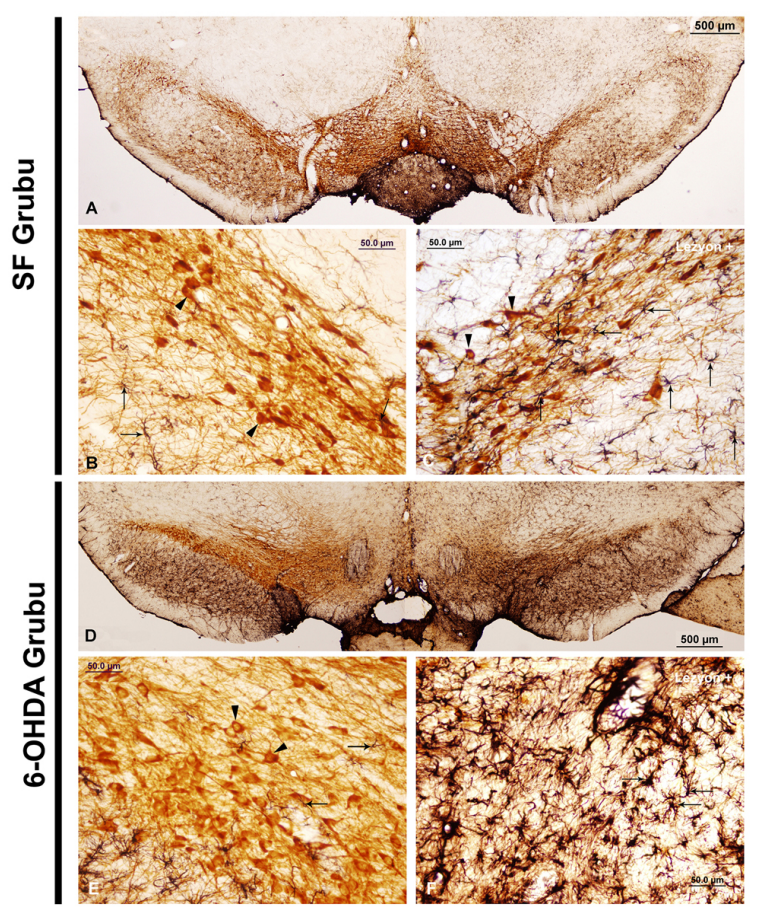

Şekil 2.

SF ve 6-OHDA gruplarlnda TH ve GFAP immünoreaktivitesi. SF (A) ve 6-OHDA (D) gruplarinda substansiya nigra alanlarının görünüşü. Enjeksiyon yapllan SN sağ tarafta gözlenmektedir. Sağlam (B ve E) ve enjeksiyon tarafinda $(C, F)$ ikili immün boyama sonucu dopaminerjik nöronlar kahverengi immünoreakviteleri (ok başl) ve astroglial hücreler de (ok) siyah immünoreaktiviteleri ile ayırt edilmektedir. TH ve GFAP immünoreaktivitesi nöron ve astrositlerin hem hücre gövdelerinde hem de uzantılarında gözlenmektedir. SF grubunda sağlam SNpc'da (B) çok az sayıda GFAP-immünoreaktif astrosit gözlenirken enjeksiyon tarafinda SNpc'da glial hücre saylsinda artış dikkati çekmektedir (C). 6-OHDA enjeksiyonu yapılan SNpc'da (D sağ taraf ve F) neredeyse hiç dopaminerjik nöron gözlenmezken sağlam tarafta (D sol taraf, E) TH immünoreaktivitesi hem hücrelerin somalarinda hem de uzantılarinda belirgin olarak izlenmektedir. 6OHDA grubunda astroglial hücreler değerlendirildiğinde sağlam tarafta (E) sadece bir kaç GFAP-pozitif astrosit ayirt edilirken, lezyonlu tarafta $(F)$ astrosit sayısındaki artışla birlikte morfolojik değişiklikler de gözlenmektedir. ( : TH-pozitif dopamin nöronları,

$$
\rightarrow \text { : GFAP-pozitif astrositler) }
$$

Her iki grupta enjeksiyon tarafindaki astrositler morfolojik açıdan da değerlendirildi (Şekil 3). SF grubunda astrosit sayısındaki artışa karşın, reaktif astrositlere özgü morfolojik özelliklere rastlanmadı. GFAP-IR astrositlerin kisa ve hipertrofik sitoplazmik uzantılardan ziyade ince uzun sitoplazmik uzantılarının olduğu ve kapillerlere yakın yerleşim gösterdikleri belirlendi (Şek 3A). 6-OHDA enjeksiyonu sonrasinda ise astrositlerin hücre gövdelerinde belirgin bir hipertrofi ile birlikte, hücre uzantılarının hem sayıca arttığı hem de bariz bir şekilde genişlediği görüldü (Şekil 3B).
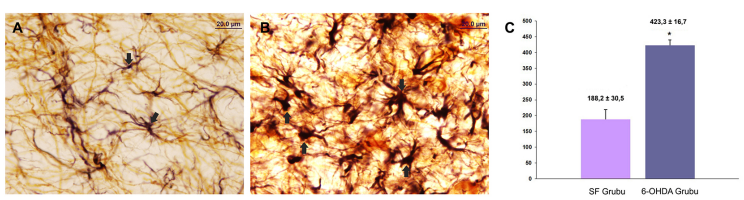

Şekil 3.

$S F$ ve 6-OHDA gruplarinda intranigral enjeksiyonlara bağll astrositlerde gözlenen morfolojik ve sayısal değişiklikler. SF enjeksiyonu (A) astrositlerde belirgin morfolojik değişikliklere neden olmazken, 6-OHDA enjeksiyonunu takiben (B) astrosit gövdelerinde hipertrofi, uzantılarında sayıca artışla birlikte kalınlaşma gözlenmektedir. (C) Enjeksiyon yapılan

SNpc'lardaki astrosit sayım sonuçları (ortalama \pm SEM, $p<0,0012$ ). ( $\rightarrow$ : astrositler)

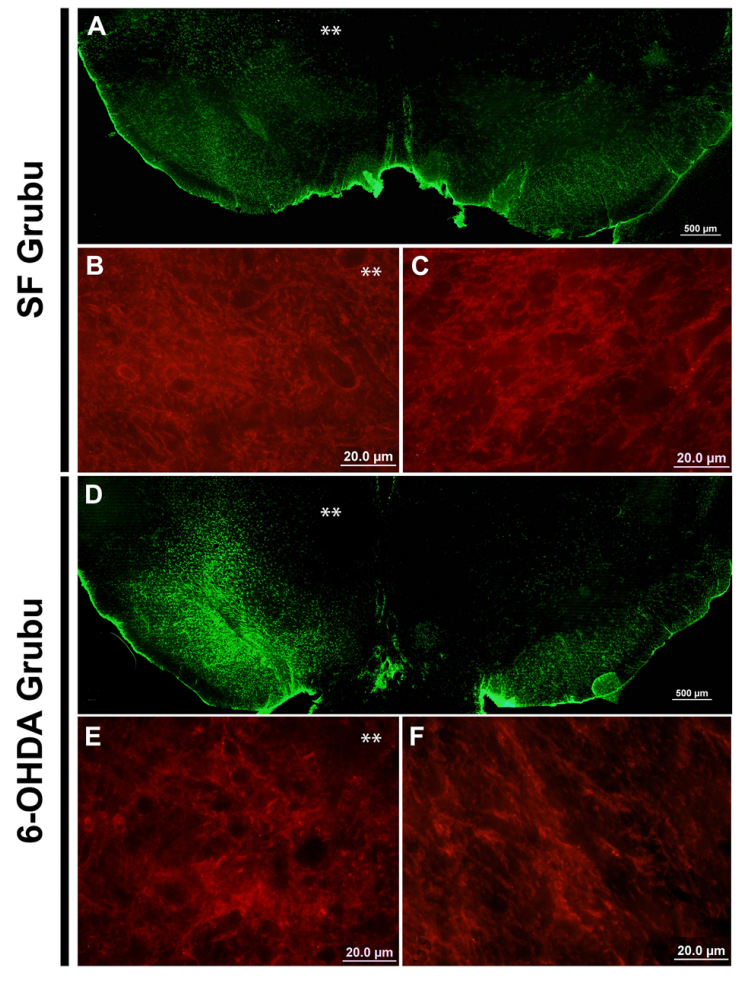

Sekil 4.

Intranigral serum fizyolojik $(A-C)$ ve 6-OHDA $(D-F)$ uygulanan deneklerde GFAP ve GLT1 proteinlerinin ekspresyonu. GFAP immünoreaktivitesi (yeşil immünofloresans) enjeksiyon taraflarinda (**) daha belirgin olarak gözlenmektedir $(A, D)$. SNpc'da GLT1 immünoreaktivitesi (kırmızı immünofloresans) özellikle nöropilde ayırt edilmektedir ( $B, C$ ve $E, F)$. GLT1 immünoreaktivite seviyesi enjeksiyonlu $(B, E)$ ve sağlam $(C, F)$ tarafta benzerdi.

6-OHDA ile Oluşturulan Lezyon Alaninda GLT1 Ekspresyonunun Değerlendirilmesi

İkili immünofloresans boyamalarında her iki grupta da SN'de hem SNpc hem de SNpr'te GLT1 immünreak- 
tivitesi gözlendi. Her iki grupta da SNpc büyük büyütmede değerlendirildiğinde GLT1 immünoreaktivitesi nöropilde ağ benzeri bir yapı şeklinde görüntülendi (Şekil 4, 5). Çok sayıda GLT1-pozitif hücre uzantısı ve punkta şeklinde işaretlenme belirlendi (Şekil 4B, C, E, F ve Şekil 5B, E). Olasılıkla nöropilar GLT1 immünoreaktivitesinin çok kuvvetli olması ve çekirdek boyamasının kullanılamaması nedeniyle astrositlerin hücre gövdelerindeki GLT1 ekspresyonu ayırt edilemedi. Üst üste çakıştırılan görüntülerde, özellikle astrositik uzantılarda GLT1 immünoreaktivitesinin GFAP immünoreaktivitesi ile kolokalize olduğu belirlendi (Şekil 5C, F). SF ve 6-OHDA grupları arasında semikantitatif olarak "ortalama gri değer" olarak değerlendirilen GLT1 ekspresyon yoğunluğu arasında farklılık gözlenmedi ( $p=0,4557)$ (Şekil 6).

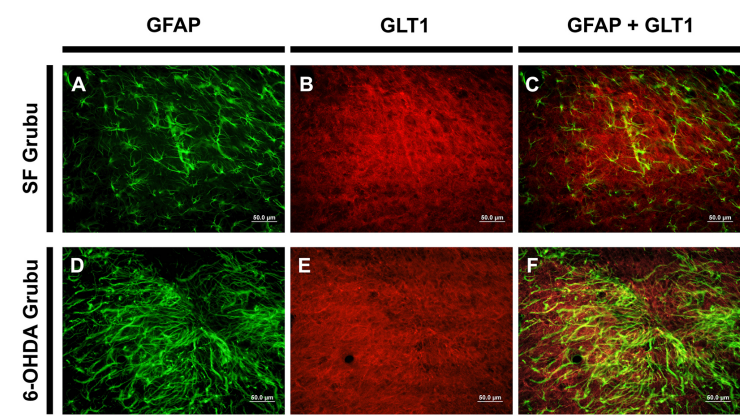

Sekil 5.

Intranigral serum fizyolojik $(A-C)$ ve 6-OHDA $(D-F)$ uygulanan deneklerde $\operatorname{GFAP}(A, D)$ ve $\operatorname{GLT1}(B, E)$ eksprese eden astrositlerin görünümü. Üst üste çakıştırllan görüntülerde (C, F) astrositlerde GLT1 ekspresyonu (sart) izlenmektedir.

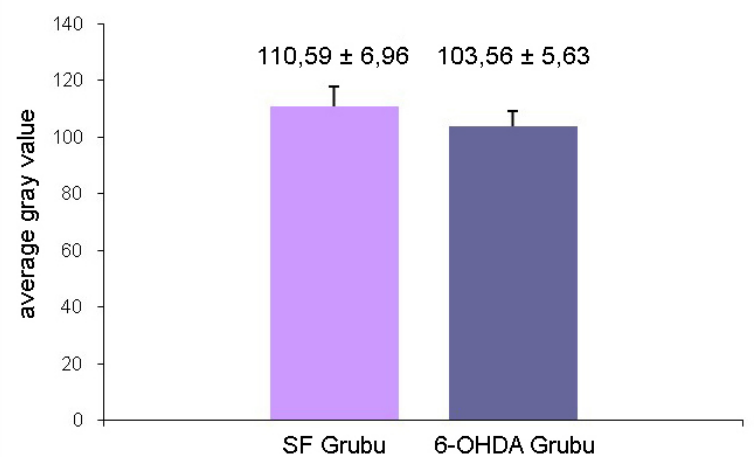

Şekil 6:

Deneklerin enjeksiyon taraflarındaki SNpc'daki GLT1 immünoreaktivite yoğunluğunun karşılaştırması. Semikantitatif analiz iki grup arasında GLT1 immünoreaktivitesinin yoğunluğu açısından fark olmadığını gösterdi. Değerler ortalama \pm SEM olarak verilmiştir $(p=0,4557)$.

\section{Tartışma ve Sonuç}

Az sayıda astrosit popülasyonu ile birlikte bulunan dopaminerjik nöronların dejenerasyona daha eğilimli oldukları ve bu nedenle de oksidatif ve enflamatuvar saldırılara karşı hassas oldukları düşünülmektedir ${ }^{48-50}$. Sunulan çalışmada kullandığımız teknik ile SNpc'da dopaminerjik nöronlara eşlik eden çok az sayıda astrosit bulunduğu gösterilmiştir. Bu sonuç literatür bulguları ile paralellik göstermektedir ${ }^{50}$. Ancak, SNpc'daki astrosit yoğunluğunun az olarak değerlendirilmesinin, astrositleri belirlemek için kullanılan GFAP antikorunun gri cevherde bulunan söz konusu hücrelerin distal uzantılarını işaretlemekte yetersiz kalmasından kaynaklandığını ve tüm hücre uzantılarını boyayan farklı bir astrositik belirteç ile tüm SN'nin astrositik uzantılarla dolu olduğunu gösteren bir çalışma bulunmaktadir ${ }^{8}$.

Normal bir beyinde astrositler, gerek nöronların sağkalımı ve fonksiyonları için gerekli olan nörotrofik faktörler ve metabolik substratlar salgılayarak, gerekse ekstrasellüler sıvıdan potansiyel toksik ajanları uzaklaştırarak, nöroproteksiyonda anahtar rol oynayan hücrelerdir ${ }^{8,51}$. MSS hasarlarında astrositler aktive olurlar (astrogliozis). Aktive olan astrositler (reaktif astrositler), morfolojik olarak hücre gövdesinin genişlemesi, astroglial uzantıların sayısında ve çaplarında artış ile karakterizedir. $\mathrm{Bu}$ yapısal değişikliklere Kir4.1, GLAST, astrositik intermediyet filamentler olan GFAP ile vimentin sentezinin up-regülasyonu ve nestinin reekspresyonu eşlik eder ${ }^{41,52,53}$. Sunulan çalışmada, 6-OHDA uygulanan deneklerin SNpc'larında, literatürde idiyopatik Parkinson hastalığı $(\mathrm{PH})$ tanısı almış hastaların postmortem örneklerinde ${ }^{54}$ ve deneysel hayvan modelinde ${ }^{55}$ olmadığı bildirilen, astroglial aktivasyon ve kantitatif olarak değerlendirilmemekle birlikte GFAP immunoreaktivitesinde artış belirlendi. $\mathrm{Bu}$ veri, 6-OHDA ile nigral lezyon oluşturulan deneklerin kullanıldığı diğer çalışmaların sonuçları ile uyumluydu ${ }^{52,56-58}$. GFAP immünoreaktif astrositlerdeki artışın nedeni ile ilgili alternatif açıklamalar vardır. McGeer ve ark ${ }^{51}$ göre SNpr gibi çevre dokulardan astrositlerin göçü, Aponso ve ark'na $^{59}$ göre, lezyon alanındaki astrogliogenez reaktif astrogliozisin nedenidir. Bazı araștırmacılar ise SN'deki astrositik reaksiyonun 6-OHDA'nın toksik etkisine ve pars kompaktadaki dopaminerjik nöronların dejenerasyonuna bağlı olduğunu düşünmektedir ${ }^{47,60}$. 1-metil-4-fenil-1,2,3,6tetrahidropiridin (MPTP) fare modellerinde, SNpc'daki dopaminerjik nöron ölüm sürecinin, astrositik aktivasyonla paralellik göstermesi ve MPTP intoksikasyonu nedeniyle çok sayıda dopaminerjik nöronun ölümünden sonra bile GFAP ekspresyonu upregüle kalması ${ }^{61}$, astrositik reaksiyonun nöronal hücre ölümünden sonra oluştuğunu düşündürmüştür ${ }^{62}$. İntranigral 6-OHDA enjeksiyonundan 12 saat sonra dopaminerjik nöronların dejenere olduğu bilgisi 1şı̆̆ altın$\mathrm{da}^{43}$, sunulan çalışmada enjeksiyondan 15 gün sonra bile belirgin astroglial reaksiyonla birlikte GFAP ekspresyonun yüksek olması reaktif gliozisin nöron ölümünden sonra olduğu yönünde değerlendirildi. 
Reaktif astrositlerin seçici ablasyonunun travmatik nöronal hasarını şiddetlendirdiği, astrosit transplantasyonunun beyin hasarını azalttığı ve hasarlanmış beyinlerde nöron ölümünün astroglial reaksiyonun oluşmadığı alanlarda daha fazla olduğu bildirilmiștir ${ }^{42}$. Bu hücrelerin eksprese ettiği nörotrofik faktörler nöronal sağkalıma aracılık ederler ve lezyonlu MSS bölgesinde nöronal tomurcuklanmayı uyarırlar $22,56,63$. Proinflamatuvar bir sitokin olan IL-1ß'nın SN'ye enjeksiyonu sonrası astrosit aktivasyonunun gözlenmesi ve SNpc'daki dopaminerjik nöronların 6-OHDA toksisitesine karşı korunması, aktive astrositlerin nöroprotektif etkisini olduğu görüşünü desteklemektedir ${ }^{64}$. Ek olarak, glutamat ve ROS'a karşı koruyucu trofik faktörlerin kaynağının glial yanıt olduğu bildirilmekte$\operatorname{dir}^{49}$. Chen ve ark ${ }^{63}$, SN'de dopaminerjik nöronların korunmasında reaktif astrositlerin önemli rol oynadığını ileri sürmektedir. İshida ve $\operatorname{ark}^{65}$, astrositlerce eksprese edilen proteaz aktive reseptör-1'in miktarının SNpc'da yükselmesinin PH'nın progresyonunda nöroproteksiyon sağladığını göstermiştir. Bu literatür verileri birlikte değerlendirildiğinde sunulan çalışmada nigral hasarda oluşan astrogliozisin dopaminerjik nöronları destekliyor olması olasıdır.

Ekstrasellüler glutamat seviyesinin yüksek kalması eksisitotoksik nöron ölümü ile sonuçlanır. Bu nedenle impulsun iletiminden sonra, glutamatın sinaptik araliktan uzaklaştırılarak glutamat konsantrasyonunun optimal seviyede kalması sağlanır. Bu süreçte astrositik glutamat taşıyıcıları işlev görür ${ }^{19}$. Astrositik GLT1, erişkin MSS'de sinaptik aralıktan glutamatın uzaklaştırılmasından asıl sorumlu glutamat taşıyıcı proteini$\mathrm{dir}^{66,67}$. İmmunofloresans ișaretleme teknikleri, SN'nin rostrokaudal ekseni boyunca GLT1 imünoreaktivitesinin homojen dağıldığını ve SNpc ve SNpr'te kabaca aynı seviyede olduğunu göstermiştir ${ }^{8}$. Yine aynı çalışma, immünoperoksidaz yöntemi ile boyanmış dokunun elektron mikroskobik incelemesi ile SN'deki GLT1-pozitif yapıların esas olarak nöropilde dağılmış astroglial uzantılara karşılık geldiğini doğrulamıştı̊ ${ }^{8}$. Nörolojik hastalıklarla bağlantılı eksisitotoksisitenin mekanizması tam olarak anlaşılamamakla birlikte EAAT'lerin disregülasyonunun nöron ölümüyle ilişkili olduğunu gösteren çalışmalar mevcuttur ${ }^{16,47,68-70}$. Striatumun glutamaterjik girdilerinin denerve edildiği deneysel modellerde, GLT1 ekpresyonun \%50 oranında azaldığ $1^{71}$, benzer șekilde kortekste oluşturulan lezyonların GLT1 ve GLAST'in \%20-30 oranında down-regülasyonuna neden olduğu gösterilmiştir ${ }^{72}$. Hayvan modellerinde parkinsonizm oluşturmak için kullanılan bir toksin olan MPTP, astrosit kültürlerine verildiğinde glutamat transportunun \%39 azaldığı, MPTP'nın ortamdan uzaklaştırılması ile taşıyıcı aktivitesinin geri geldiği gösterilmiştir ${ }^{73}$. Dervan ve ark. (74), MPTP uygulanmış farelerde striatumda GLT1'in down-regüle olduğunu göstermiştir. GLT1 aktivitesinin blokajı ile nörodejenerasyon oluşması da glutamat taşıyıcılarının nörolojik hastalıkların gelişiminde rol oynadıkları düşüncesini desteklemektedir. Substrat inhibitör PDC ve non-substrat inhibitör DLTBOA'nın hipokampusa ve striatuma direkt enjeksiyonu ile glutamat taşıyıcılarının inhibe edilmesinin nöron ölümüne neden olduğ $\mathrm{u}^{75}$ ve GLT1-seçici bloker WAY-855'in sıçan hipokampusunda in vivo ve in vitro nörotoksisite oluşturulabileceği ${ }^{76}$ gösterilmiştir. Siçan ve farelerdeki homoloğu glutamat taşıyıcisıilişkili protein 3-18 (GTRAP3-18) olan JWA geninin astrositlerdeki selektif delesyonunun, MPTP/ probenesid fare modelinde motor işlev bozukluğunu ile dopaminerjik nörodejenerasyonu şiddetlendirdiği ve GLT1 ekpresyonunu azalttığı gösterilmiştir ${ }^{36}$. Deneysel sıçan ve fare Parkinson modellerinde GLT1 mRNA ve protein seviyeleri ile ilgili çelișen bulguları olan çalışmalar bulunmaktadır. 6-OHDA modelinde GLT1 mRNA seviyesinde değişiklik olmadığı bildirilirken, ${ }^{77,78}$, MPTP modelinde, astrosit sayısında artış ile birlikte GLT1 mRNA ve protein seviyelerinde azalma oldu$\mathrm{gu}^{36}$ gösterilmiştir. İntrastriatal 6-OHDA ile dopamin denenervasyonundan sonra striatal GLT1 protein ekspresyonu azalırken, nigral ekspresyonun değişmediği gösterilmiştir ${ }^{47}$. Ancak, bu çalışmada GFAP-IR astrositlerin kantitatif değerlendirmesi ile ilgili veriler açık değildir. Çalışmamızda, intranigral 6-OHDA ile oluşturulan dopaminerjik nöron hasarından sonra SNpc'da astroglial reaksiyon oluşmasına karşın GLT1 ekspresyonunun değişmediği immünohistokimyasal olarak gösterilmiştir ve astroglial reaksiyona karşın GLT1 protein ekspresyon seviyesinin değişmemesi, GLT1 down-regülasyonu olarak değerlendirilmiştir. Ancak, kullandığımız yöntem ve analiz yaklaşımının olası bir GLT1 artışını belirleyebilecek hassaslıkta olmayabileceği de göz ardı edilemeyecek bir olasılıktır. Reaktif astrositlerin nöron ölümünden 15 gün sonra tüm SNpc'da belirgin olması, glial reaksiyonun yalnızca uygulanan maddenin toksik etkisine ve/veya nöron ölümüne bağlanamayacağı, aksine astrositlerin koruyucu etkisinin olabileceği yönündeki bulguları desteklemektedir.

Sonuç olarak; SNpc'da 6-OHDA ile oluşturulan dopaminerjik nöron hasarı sonrası immünohistokimyasal yöntemlerle belirlediğimiz astrogilozis ve glial aktivasyona karşın GLT1 protein ekspresyonunun değişmemesi, astrositlerin ve/veya glutamat taşıyıcısı GLT1'in, SNpc'da dopaminerjik nöron ölümü ile karakterize Parkinson hastalığının etyopatolojinde rol oynayabileceği akla getirmiș ve astrositlerin sağkalımı ve/veya fonksiyonlarının korunmasının, nöron kaybı ile karakterize MSS hastalıklarının sağaltımı için yeni terapötik ajan arayışına yönelik çalışmalarda hedef yaklaşımlar olabileceğini düşündürmüştür.

\section{Teşekkürler}

$\mathrm{Bu}$ çalışma TÜBITTAK tarafindan desteklenmiştir (106S029 [SBAG 3307]). 


\section{Z. Minbay, ark.}

Etik Kurul Onay Bilgisi:

Onaylayan Kurul: Bursa Uludağ Üniversitesi Hayvan Bakım ve Kullanım Komitesi

Onay Tarihi: 29.12 .2005

Karar No: 29.12.2005/1

\section{Kaynaklar}

1. Chen LW, Wei, LC, Lang B, Ju G, Chan YS. Differential expression of AMPA receptor subunits in dopamine neurons of the rat brain: a double immunocytochemical study,. Neuroscience $2001 ; 106: 149-160$.

2. Chinta SJ, Andersen JK. Dopaminergic Neurons. Int J Biochem Cell Biol 2005;37: 942-946.

3. Vallone D, Picett, R, Borrelli E. Structure and function of dopamine receptors. Neurosci Biobehav Rev 2000;24:125-132.

4. Bjorklund A, Dunnett SB. Dopamine neuron systems in the brain: an update. Trends Neurosci 2007;30:194-202.

5. Vivo M, Camon L, de Vera N, Martinez E. Lesion of substantia nigra pars compacta by the glur5 agonist ATPA. Brain Res 2002;955:104-114.

6. Chatha BT, Bernard V, Streit P, Bolam JP. Synaptic localization of 1onotropic glutamate receptors in the rat substantia nigra. Neuroscience 2000; 101:1037-1051.

7. Fallon JH, Loughlin SE. Substantia Nigra. In: The Rat Nervous System. Paxinos G (ed). San Diego: Academic Press; 1995. 215-237

8. Kessler JP, Salin P, Kerkerian-Le Goff L. Glutamate transporter 1-expressing glia in the rat substantia nigraMorphometric analysis and relationships to synapses. Glia 2020;68:2028-2039.

9. Paladini CA, Tepper JM. Neurophysiology of substantia nigra dopamine neurons: modulation by GABA and glutamate. In Handbook of Basal Ganglia Structure and Function. Steiner H, Tseng KY (eds). 2nd edition. London: Academic Press; 2016. 350

10. Iribe Y, Moore K, Pang KC, Tepper JMSubthalamic stimulation-1nduced synaptic responses in substantia nigra pars compacta dopaminergic neurons in vitro. J. Neurophysiol 1999;82:925-933.

11. Geisler S, Wise RA. Functional implications of glutamatergic projections to the ventral tegmental area. Rev Neurosci 2008; 19: 227-244

12. Watabe-Uchida M, Zhu L, Ogawa SK, Vamanrao A, Uchida N Whole-brain mapping of direct inputs to midbrain dopamine neurons. Neuron 2012;74:858-873.

13. Lobo MK, Itri JN, Cepeda C, Chavira CA, Levine MS. Ionotropic glutamate receptor expression and dopaminergic modulation in the developing subthalamic nucleus of the rat: an $1 \mathrm{~m}-$ munohistochemical and electrophysiological analysis. Dev Neurosci 2003;25:384-383.

14. Kim JH, Min KJ, Seol W, Jou I, Joe EH. Astrocytes in injury states rapidly produce anti-inflammatory factors and attenuate microglial inflammatory responses. J Neurochem 2010; 115:1161-1171.

15. Anderson CM, Swanson RA. Astrocyte glutamate transport: review of properties, regulation, and physiological functions. Glia 2000; 32: 1-14.

16. Maragakis NJ, Rothstein JD. Glutamate transporters: Anima models to neurologic disease. Neurobiol Dis 2004;15:461-473.

17. Plaitakis A, Shashidharan P. Glutamate transport and metabolism in dopaminergic neurons of substantia nigra: Implications for the pathogenesis of Parkinson's Disease. J Neurol 2000;247(Suppl 2): II25-II35.
18. Shimamoto K, LeBrun B, Yasuda-Kamatani Y, Sakaitani M, Shigeri Y, Yumoto N, Nakajima T. DL-Threo-betaBenzyloxyaspartate, a potent bBlocker of excitatory amino acid transporters. Mol Pharmacol 1998;53:195-201.

19. Pajarillo E, Rizor A, Lee J, Aschner M, Lee E. The role of astrocytic glutamate transporters GLT-1 and GLAST in neurological disorders: Potential targets for neurotherapeutics. Neuropharmacology 2019;161:107559.

20. Walker CK, Roche JK, Sinha V, Roberts RC. Substantia nigra ultrastructural pathology in schizophrenia. Schizophrenia Research 2018;197:209-218.

21. Kanai Y, Hediger MA. Primary structure and functional characterization of a high-affinity glutamate transporter. Nature 1992;360:467-471.

22. Pines G, Danbolt NC, Bjoras M, Zhang Y, BendahanA, Eide L, Koepsell H, Storm-Mathisen J, Seeberg E, Kanner BI. Cloning and expression of a rat brain L-glutamate transporter. Nature, 1992;360:464-467.

23. Lehre KP, Levy LM, Ottersen OP, Storm-Mathisen J, Danbolt NC. differential expression of two glial glutamate transporters in the rat brain: quantitative and immunocytochemical observations J Neurosci 1995;15:1835-1853.

24. Holmseth S, Dehnes Y, Huang YH, Follin-Arbelet VV, Grutle NJ, Mylonakou MN, Plachez C, Zhou Y, Furness DN, Bergles DE, Lehre KP, Danbolt NC. The density of EAAC1 (EAAT3) glutamate transporters expressed by neurons in the mammalian CNS. J Neurosci 2012;32:6000-6013.

25. Dehnes Y, Chaudhry FA, Ullensvang K, Lehre KP, StormMathisen J, Danbolt NC. The glutamate transporter EAAT4 in rat cerebellar Purkinje cells: a glutamate-gated chloride channel concentrated near the synapse in parts of the dendritic membrane facing astroglia. J Neurosci 1998;18:3606-3619.

26. Yamada K, Watanabe M, Shibata T, Tanaka K, Wada K, Inoue Y. EAAT4 is a post-synaptic glutamate transporter at Purkinje cell synapses. Neuroreport 1996;7:2013-2017.

27. Nagao S, Kwak S, Kanazawa I. EAAT4, a glutamate transporter with properties of a chloride channel, is predominantly localized in Purkinje cell dendrites, and forms parasagittal compartments in rat cerebellum. Neuroscience 1997;78:929. 933.

28. Sulzer, D, Joyce MP, Lin L, Geldwert D, Haber SN, Hattori T, Rayport S. Dopamine neurons make glutamatergic synapses in vitro. J Neurosci 1998;18:4588-4602.

29. Albers DS, Weiss SW, Iadarola MJ, Standaert DG. Immunohistochemical localization of N-Methyl-D-Aspartate and Alpha-Amino-3-Hydroxy-5-Methyl-4-Isoxazolepropionate receptor subunits in the substantia nigra pars compacta of the rat. Neuroscience 1999; 89: 209-220.

30. Zhang Y, Tan F, Xu P, Qu S. Recent Advance in the relationship between excitatory amino acid transporters and Parkinson's Disease. Neural Plast 2016;2016:8941327.

31. Booth HDE, Hirst WD, Wade-Martins R. The role of astrocyte dysfunction in Parkinson's Disease pathogenesis. Trends Neurosci 2017;40:358-370

32. Perez-Costas E, Melendez-Ferro M, Rice MW, Conley RR, Roberts RC. Dopamine pathology in schizophrenia: analysis of total and phosphorylated tyrosine hydroxylase in the substantia nigra. Front Psychiatry 2012;3:31

33. Andreassen OA, Ferrante RJ, Aamo TO, Beal MF, Jørgensen HA. Oral dyskinesias and histopathological alterations in substantia nigra after long-term haloperidol treatment of old rats. Neuroscience 2003;122:717-725.

34. Rao, VL, Bowen KK, Dempsey RJ. Transient focal cerebral 1schemia down-regulates glutamate transporters GLT-1 and EAAC1 expression in rat brain. Neurochem Res 2001;26:497502. 


\section{Parkinson Hastalığı Modelinde Astrogliozis ve GLT1}

35. Hoshi A, Tsunoda A, Yamamoto T, Tada M, Kakita A, Ugawa Y. Altered expression of glutamate transporter-1 and water channel protein aquaporin-4 in human temporal cortex with Alzheimer's disease. Neuropathol Appl Neurobiol 2018;44:628638.

36. Wang R, Zhao X, Xu J, Wen Y, Li A, Lu M, Zhou J. Astrocytic JWA deletion exacerbates dopaminergic neurodegeneration by decreasing glutamate transporters in mice. Cell Death Dis 2018;9:1-15.

37. Vanoni C, Massari S, Losa M, Carrega P, Perego C, Conforti L, Pietrini G. Increased internalisation and degradation of GLT-1 glial glutamate transporter in a cell model for familial amyotrophic lateral sclerosis (ALS). J Cell Sci 2004;117(Pt 22):5417-5426.

38. Aoyama K, Matsumura N, Watabe M, Nakaki T. Oxidative stress on EAAC1 is involved in MPTP-induced glutathione depletion and motor dysfunction. Eur J Neurosci 2008;27:20-30.

39. Kobayashi E, Nakano M, Kubota K, Himuro N, Mizoguchi S, Chikenji T, Otani M, Mizue Y, Nagaishi K, Fujimiya M. Activated forms of astrocytes with higher GLT-1 expression are associated with cognitive normal subjects with Alzheimer pathology in human brain. Sci Rep 2018;8:1712.

40. Zhang Y, Meng X, Jiao Z, Liu Y, Zhang X, Qu S. Generation of a novel mouse model of Parkinson's Disease via targeted knockdown of glutamate transporter GLT-1 in the substantia nigra. ACS Chem Neurosci 2020;11:406-417.

41. Joe EH, Choi DJ, An J, Eun JH, Jou I, Park S. Astrocytes, microglia, and Parkinson's Disease. Exp Neurobiol 2018;27:7787

42. Jeong HK, Ji KM, Min KJ, Choi I, Choi DJ, Jou I, Joe EH. Astrogliosis is a possible player in preventing delayed neuronal death. Mol Cells 2014;37:345-355.

43. Tieu K. A guide to neurotoxic animal models of Parkinson's disease. Cold Spring Harb Perspect Med 2011;1:a009316.

44. Bjorklund A, Dunnett SB. The Amphetamine induced rotation test: A re-assessment of its use as a tool to monitor motor impairment and functional recovery in rodent models of Parkinson's disease. J Parkinsons Dis 2019;9:17-29.

45. Paxinos, G. and Watson, C. (eds) The Rat Brain in Stereotaxic Coordinates San Diego. Academic Press, 2004.

46. Sze, SC, Wong CK, Yung KK. Modulation of the gene expression of N-Methyl-D-Aspartate Receptor NR2B Subunit in the rat neostriatum by a single dose of specific antisense oligodeoxynucleotide. Neurochem Int 2001;39:319-327.

47. Chung EK, Chen LW, Chan YS, YungKK. Downregulation of glial glutamate transporters after dopamine denervation in the striatum of 6-hydroxydopamine-lesioned rats. J Comp Neurol 2008; 511:421-437.

48. Hirsch EC. Glial cells and Parkinson's Disease, J Neurol 2000; 247(Supp1 2): II58-II62.

49. Vila M, Jackson-Lewis V, Guegan C, Wu DC, Teismann P, Choi DK, Tieu K, Przedborski S. The role of glial cells in Parkinson's Disease,. Curr Opin Neurol 2001;14:483-489.

50. Ji KA, Eu M Y, Kang SH, Gwag BJ, Jou I, Joe EH. Differential neutrophil infiltration contributes to regional differences in brain inflammation in the substantia nigra pars compacta and cortex. Glia 2008;56:1039-1047.

51. McGeer PL, McGeer EG. Glial reactions in Parkinson's Disease. Mov Disord 2008; 23:474-483.

52. Gomide VC, Silveira GA, Chadi G. Transient and widespread astroglial activation in the brain after a striatal 6-OHDAinduced partial lesion of the nigrostriatal system. Int J Neurosci 2005;115:99-117.

53. Pekny M, Nilsson M. Astrocyte activation and reactive gliosis. Glia $2005 ; 50: 427-34$.
54. Mirza B, Hadberg H, Thomsen P, Moos T. The absence of reactive astrocytosis is indicative of a unique inflammatory process in Parkinson's Disease. Neuroscience 2000;95:425-432.

55. Depino AM, Earl C, Kaczmarczyk E, Ferrari C, Besedovsky H, del Rey A, Pitossi FJ, Oertel WH. Microglial activation with atypical proinflammatory cytokine expression in a rat model of Parkinson's Disease, Eur J Neurosci 2003;18:2731-2742.

56. Rodrigues RW, Gomide VC, Chadi G. Astroglial and microglial reaction after a partial nigrostriatal degeneration induced by the striatal injection of different doses of 6-hydroxydopamine. Int.. J. Neurosci 2001;109:91-126.

57. Rodrigues RW, Gomide VC, Chadi G. Astroglial and microglial activation in the wistar rat ventral tegmental area after a single striatal injection of 6-hydroxydopamine, Int J Neurosci 2004;114:197-216.

58. Knyihar-Csillik E, Chadaide Z, Mihaly A, Krisztin-PevaB, Fenyo R, Vecsei L. Effect of 6-hydroxydopamine treatment on kynurenine aminotransferase-I (KAT-I) immunoreactivity of neurons and glial cells in the rat substantia nigra. Acta Neuropathol 2006;112:127-137.

59. Aponso PM, Faull RL, Connor B, Increased progenitor cell proliferation and astrogenesis in the partial progressive 6Hydroxydopamine Model of Parkinson's Disease. Neuroscience 2008;151:1142-1153.

60. Gomide V, Bibancos T, Chadi G. Dopamine cell morphology and glial cell hypertrophy and process branching in the nigrostriatal system after striatal 6-OHDA analyzed by specific sterological tools. Int J Neurosci 2005;1 15:557-582.

61. Liberatore G, Jackson-Lewis V, Vukosavic S, Mandir AS, Vila M, McAuliffe WJ, Dawson VL, Dawson TM, Przedborski S. Inducible nitric oxide synthase stimulates dopaminergic neurodegeneration in the MPTP model of Parkinson's disease. Nat Med 1999;5:1403-1409.

62. Przedborski S, Jackson-Lewis V, Djaldetti R, Liberatore G, Vila M, Vukosavic S, Almer G. The parkinsonian toxin MPTP: action and mechanism. Restor Neurol Neurosci 2000;16:135142 .

63. Chen LW, Yung KL, Chan YS. Reactive astrocytes as potential manipulation targets in novel cell replacement therapy of Parkinson's Disease, Curr Drug Targets 2005;6:821-833.

64. Saura J, Pares M, Bove J, Pezzi S, Alberch J, Marin C, Tolosa $\mathrm{E}$, Marti MJ. Intranigral infusion of interleukin-1beta activates astrocytes and protects from subsequent 6-hydroxydopamine neurotoxicity, J Neurochem 2003;85:651-661.

65. Ishida Y, Nagai A, Kobayashi S, Kim SU. Upregulation of protease-activated receptor-1 in astrocytes in Parkinson Disease: Astrocyte-mediated neuroprotection through increased levels of glutathione peroxidase. J Neuropathol Exp Neurol 2006;65:66-77.

66. Danbolt NC. Glutamate uptake. Prog Neurobiol 2001;65:1-105.

67. Karki P, Smith K, Johnson Jr J, Aschner M, Lee E. Role of transcription factor yin yang 1 in manganese-induced reduction of astrocytic glutamate transporters: putative mechanism for manganese-induced neurotoxicity. Neurochem Int 2015;88:5359.

68. Karki P, Lee E, Aschner M. Manganese neurotoxicity: a focus on glutamate transporters. Ann Occup Environ Med 2013; 25: 4.

69. Hazell AS, Rao KV, Danbolt NC, Pow DV, Butterworth RF. selective down-regulation of the astrocyte glutamate transporters GLT-1 and GLAST within the medial thalamus in experimental Wernicke's Encephalopathy. J Neurochem 2001;78:560568.

70. Rao KV, Dogan A, Todd KG, BowenKK, Kim BT, Rothstein JD, Dempsey RJ. Antisense knockdown of the glial glutamate transporter GLT-1, but not the neuronal glutamate transporter EAAC1, exacerbates transient focal cerebral ischemia-induced neuronal damage in rat brain. J Neurosci 2001;21:1876-1883. 


\section{Z. Minbay, ark.}

71. Ginsberg SD, Martin LJ, Rothstein JD. Regional deafferentation down-regulates subtypes of glutamate transporter proteins J Neurochem 1995;65:2800-2803.

72. Levy LM, Lehre KP, Walaas SI, Storm-Mathisen J, Danbolt NC. Down-regulation of glial glutamate transporters after glutamatergic denervation in the rat brain. Eur $\mathrm{J}$ Neurosci 1995; 7:2036-2041.

73. Hazell AS, Itzhak Y, Liu H, Norenberg MD. 1-Methyl-4Phenyl-1,2,3,6-Tetrahydropyridine (MPTP) decreases glutamate uptake in cultured astrocytes. J Neurochem 1997;68:22162219.

74. Dervan AG, Meshul CK, Beales M, McBean GJ, Moore C, Totterdell S, Snyder AK, Meredith GE. Astroglial plasticity and glutamate function in a chronic mouse model of Parkinson's Disease. Exp Neurol 2004;190:145-156.

75. Montiel T, Camacho A, Estrada-Sanchez AM, Massieu L. Differential effects of the substrate inhibitor L-transpyrrolidine-2,4-dicarboxylate (PDC) and the non-substrate inhibitor DL-Threo-Beta-Benzyloxyaspartate (DL-TBOA) of
Glutamate transporters on neuronal damage and extracellular amino acid levels in rat brain in vivo. Neuroscience 2005;133:667-678.

76. Selkirk JV, Nottebaum LM, Vana AM, Verge GM, Mackay KB, Stiefel TH, Naeve GS, Pomeroy JE, Petroski RE, Moyer J, Dunlop J, Foster AC. Role of the GLT-1 subtype of glutamate transporter in glutamate homeostasis: the GLT-1-preferring inhibitor WAY-855 produces marginal neurotoxicity in the rat hippocampus Eur J Neurosci 2005;21:3217-3228.

77. Lievens JC, Salin P, Nieoullon A, Kerkerian-Le Goff L. Nigrostriatal denervation does not affect glutamate transporter mRNA expression but subsequent levodopa treatment selectively increases GLT1 mRNA and protein expression in the rat striatum. J Neurochem 2001;79:893-902.

78. Robelet S, Melon C, Guillet B, Salin P, Kerkerian-Le Goff L. Chronic L-DOPA treatment increases extracellular glutamate levels and GLT1 expression in the basal ganglia in a rat model of Parkinson's Disease. Eur J Neurosci 2004;20:1255-1266. 